\title{
Feasibility and Outcomes of Paid Undergraduate Student Nurse Positions
}

Lucia Gamroth, RN, PhD

Associate Professor, University of Victoria School of Nursing

Victoria, BC

Claire Budgen, RN, PhD

Associate Professor, University of British Columbia Okanagan

Kelowna, BC

Mary Lougheed, RN, MN

Senior Instructor, University of Victoria School of Nursing

Victoria, BC

\section{Abstract}

An Undergraduate Nurse Employment Demonstration Project (UNDP) was implemented in four Health Service Areas in British Columbia with a concurrent evaluation study. This demonstration project comprised the development and implementation of a new position in the $\mathrm{BC}$ healthcare system. The position enabled third- and fourth-year nursing students to be employed at their level of education. The purposes of the evaluation were to explore the feasibility and outcomes of this type of paid undergraduate student nurse employment. The three-year project and evaluation included both implementation and outcome analysis. The implementation evaluation design was descriptive and prospective, involving multiple data sources. The outcome evaluation design was quasi-experimental, with intervention and comparison groups. Learning outcomes for undergraduate nurses were increased confidence, organizational ability, competency and ability to work with a team. Workplace outcomes were increased unit morale, help with workload and improved patient care. New graduates with undergraduate nurse experience reported less time required for orientation and transition than other graduates who did not have this experience, and workplace nurses viewed these new graduates 
as more job-ready than other new graduates. After 21 months, new graduates with undergraduate nurse experience were less likely to move to other employment than other new graduates. Results from the four Health Service Areas indicated that the paid undergraduate nurse position was feasible and that outcomes benefited students, new graduates and workplaces. The undergraduate nurse position is now being implemented throughout all Health Service Areas in British Columbia.

By 2000, concerns in British Columbia about the nursing workforce, workplace and patient safety had escalated to the point where diverse stakeholder groups were prepared to work together in new ways to prepare nursing graduates to be more job-ready, to recruit and retain new graduates and to retain existing nurses. Stakeholder groups were administrators, labour organizations, professional associations, educators and government.

One idea to support job readiness and retention focussed on the feasibility of implementing cooperative education for nursing students. The effort was unsuccessful owing to lack of funding, but resulted in a review of the literature on cooperative education and other work-study programs. Cooperative education connects classroom learning with paid work experience for the purpose of enhancing students' education (Fitt and Heverly 1990; Heinemann and De Falco 1992; Ryder 1987). Reported benefits for students were improved job preparation and graduate retention (Ishida et al. 1998), additional staffing and reduction in orientation time (Cusack 1990; Ishida et al. 1998), increased practice judgment (Cusack 1990; Siedenberg 1989) and better workload management (Ross and Marriner 1985).

A work-study model reported in the literature offered benefits similar to those of cooperative education, with greater flexibility in design. An example was the University of Texas Health Science Center at Houston's collaborative work-study scholarship program with local hospitals (Kee and Ryser 2001). Students in second clinical semesters were employed as unlicensed personnel by hospitals. The students, as unlicensed personnel, worked to the level of their nursing preparation. Reported benefits for students were academic credit, financial assistance, interaction with multidisciplinary teams, opportunity to refine clinical skills, understanding of nurses' roles and guaranteed interview for positions on graduation (Kee and Ryser 2001). Benefits for practice organizations were skilled help, the opportunity to recruit new nurses and increased interaction with a university nursing program. 
While nurse education stakeholders in British Columbia were exploring options, the concept of undergraduate student nurse employment was initiated by a group of fourth-year students at the University of Victoria who were completing the course "Nurses Influencing Change." The students were concerned about having enough practice experience to meet increasing nursing competency requirements and their survival as new graduates given workplace realities. Debt load also was a concern because extensive student practicum time limited opportunities for paid employment during the nursing education program. Students found that the idea of paid undergraduate nurse positions, based on the student employment model in Alberta, was supported by nurse leaders, many practising nurses and nursing faculty who also were concerned about meeting patient care standards and adequately preparing nursing students.

In 2000, the BC Ministry of Health Services funded an Undergraduate Nurse Demonstration Project (UNDP) - one type of paid employment for undergraduate student nurses - in four Health Service Areas linked with four schools of nursing. A concurrent three-year evaluation study examined the feasibility and outcomes of the UNDP (Gamroth et al. 2004). This paper summarizes the findings of the evaluation.

\section{Evaluation Research}

The purposes of the evaluation were to explore the ways the UNDP was implemented, determine outcomes and ascertain future plans arising from the project. Early outcomes included student learning and workplace outcomes during implementation. These early outcomes were viewed as indicators foundational to longer-term outcomes. Longer-term outcomes included job readiness of new graduates, recruitment and retention of new graduates and retention of existing nurses.

Three questions guided the evaluation: (1) How was the UNDP implemented in each Health Service Area? (2) What were the outcomes of the UNDP? (3) What are the implications, plans and possibilities for future undergraduate student nurse employment programs?

\section{Methods}

The evaluation study included both implementation (process) and outcome analysis. The implementation evaluation focussed on research questions one and three, the outcome evaluation on question two. The evaluation design used multiple data sources: workplace nurses, students and faculty. Additional data sources were key healthcare and nursing practice stakeholders in the province and documents associated with the demonstration project. 
The evaluation was longitudinal, with implementation data collected over three years and outcome data collected for two cohorts of new graduates over two years: 2002 graduates at nine and 21 months and 2003 graduates at nine months. The outcome component used a quasi-experimental design with intervention (undergraduate nurse experience) and comparison (no undergraduate nurse experience) groups. The intervention group is reported as "UGN" participants and the comparison group is reported as "other" participants.

The research team included university researchers, practice representatives from participating Health Service Areas and faculty representatives from linked schools of nursing. Action research is particularly suited to collaborative evaluation involving multiple partners. According to Green et al. (1995: 3), common characteristics of action research are (a) collaboration between researchers and the community in each stage of research, (b) a reciprocal educational process and (c) an emphasis on taking action on the issue under study. Consistent with these characteristics, the team communicated regularly to shape the implementation and evaluation and to use early findings to improve implementation of the project. Timely use of findings (knowledge transfer) was further supported by the dissemination of six-month and yearly evaluation reports to participating healthcare agencies, educational institutions and policy makers.

The sample for the implementation evaluation included 462 workplace nurses, 123 students, six key healthcare and nursing leaders and 42 faculty members. Sample selection was inclusive, i.e., the invitation to participate was issued to all staff on nursing units where UGNs were employed, all students who were employed as UGNs and all faculty members who taught UGNs. The sample for outcome evaluation comprised 40 workplace nurses, 173 new graduates and seven faculty members. The workplace nurse and faculty samples were smaller than the implementation sample because direct experience with new graduates who had been UGNs was required. All graduates who were UGNs and all graduates who were not UGNs (comparison group) were invited to participate. The implementation and outcomes samples were judged to be representative based on inclusive sample selection, high response rates and variance in responses. Documents sampled and examined in the evaluation included the undergraduate nurse position description, Registered Nurses Association of $\mathrm{BC}(\mathrm{RNABC})^{\star}$ criteria for undergraduate nurse and letters of agreement between the $\mathrm{BC}$ Nurses Union and health authorities.

Data were collected using questionnaires, key informant interviews and focus groups. Measurement tools were developed by the researchers from previously

\footnotetext{
* The RNABC became the College of Registered Nurses of British Columbia in 2006.
} 
well-tested tools (CNP 2000, RNABC 2002, 2003) and pilot tested to support validity. Strategies were developed to ensure consistency in data collection (e.g., focus group training, determining qualifications of participants, guidelines for recording field notes) and were used throughout. Validity also was supported by triangulation of data sources (i.e., workplace nurses, managers, students, nursing faculty, new graduates and healthcare leaders), providing multiple views on the phenomena of interest. Quantitative data were analyzed using Statistical Package for the Social Sciences (SPSS Inc., Version 11.5 for Windows 2002). Qualitative data were analyzed for themes by three researchers; themes were cross-checked by the research team and validated by participants. This evaluation study rested on the assumption that self-report provides data that are valid descriptions of participants' views and experiences.

\section{Results}

\section{How was the UNDP implemented in Health Service Areas?}

Key informants described a unique and essential collaboration between various stakeholders in what they called a "window of opportunity." Stakeholders included the BC Nurses Union, Registered Nurses Association of BC, Health Employers Association of BC, schools of nursing, nurses and student nurses. These stakeholders shared an interest in creating a paid undergraduate student nurse position within the provincial healthcare system and valued the contribution of each stakeholder in the process. Stakeholders identified and addressed barriers to implementation (e.g., changing RNABC rules, creating an undergraduate nurse position description, developing letters of agreement between the BC Nurses Union and Health Employers Association). Stakeholders offered leadership within their realms of influence and took advantage of funding opportunities. Stakeholders credited the nursing and human resources leaders as setting the stage for "working to the possible." Stakeholders also described an excitement about working together towards an innovative idea in a timely manner.

All undergraduate employment positions were under the supervision of a registered nurse supernumerary to regular staffing, required concurrent enrollment in a nursing education program and were based on a province-wide position description that included skills over and above those of nursing aide or practical nurse positions. There were no formal links to the nursing education program (Gamroth et al. 2004).

Implementation varied across Health Service Areas: hours of work, type of unit (medical-surgical, psychiatry-mental health, maternal-newborn, paediatrics, long-term care), level of student educational preparation (year 3 or 4 of nursing program), duration of employment and day-to-day coordination. The duration of employment included three patterns: summer only, summer plus additional hours 
and ongoing employment throughout the year. In the summer and summer-plus models, students applied each year. In the ongoing model, students could remain in undergraduate nurse positions until they graduated without re-applying.

Some comments from nurses

"The immediate result is improved patient care and patient satisfaction."

"[UGNs] created hope for the existing staff. For me, this changed the atmosphere."

"... joy on the faces of the nurses when they walk in and the undergraduates are working..."

"When they are as competent as our [UGNs] were, it allowed us more time with our patients."

"It gives [RNs] time to talk to the families

... deal with problems that families may have..."
Each of the Health Service

Areas had one nurse who was the Practice Representative on the research team and the contact person for project implementation. Three of these nurses fulfilled the implementation role in addition to their regular responsibilities, and one had a part-time position dedicated to the project.

Early implementation challenges were threefold: confusion related to the new role of a student as a UGN

employee, tracking of required RNABC student membership to ensure current enrollment in a nursing program and occasional violation of supernumerary status (i.e., use of UGNs to replace staff). These challenges largely disappeared in the second and third year of the demonstration project.

Not every UGN experienced success in the role. Over the three years of the evaluation study, one was fired, two were not re-hired, and two were not given hours because staff members were not satisfied with their performance. Performance evaluation for UGNs was a concern, as there was no formal evaluation system developed during the project; thus, the variation in staff response when UGNs had difficulties. In a few situations, the fit between unit needs and UGN capabilities was unsatisfactory, and changes in placement were successfully made. In spite of the challenges of implementation, the undergraduate nurse position continued to have strong support from all stakeholders.

\section{What were the outcomes of the UNDP?}

Early outcomes included learning outcomes for students from working as UGNs and workplace outcomes from having UGNs on units. Longer-term outcomes included new graduate recruitment, transition to first RN position, job readiness and retention. Retention of existing nurses also was an outcome of interest. 
Learning outcomes for the UGN student. Workplace, UGN and faculty participants reported that UGNs increased in confidence, organizational abilities, skills, competencies and teamwork (Table 1). Workplace and UGN participants identified the importance of practical experience for student familiarization with the workplace and the significance of students working and being paid within a nursing role commensurate with their level of educational preparation.

Workplace participants also stated that working as a UGN enabled students to progress from their individual levels of competence, thus enhancing their practice. In other words, some students who initially were average in their practice became very good and students who were initially very good in their practice became excellent.

\begin{tabular}{|c|c|c|}
\hline Learning for UGI & students & \\
\hline Workplace Perceptions of UGNs & UGN Self-Perceptions & Faculty Perceptions of UGNs \\
\hline $\begin{array}{l}\text { Noticeable improvement } \\
\text { in practice }\end{array}$ & $\begin{array}{l}\text { Seeing how much I } \\
\text { advanced }\end{array}$ & $\begin{array}{l}\text { Increased confidence, skills, } \\
\text { competency, organization }\end{array}$ \\
\hline $\begin{array}{l}\text { Becoming better team } \\
\text { members }\end{array}$ & $\begin{array}{l}\text { Becoming part of } \\
\text { a team }\end{array}$ & $\begin{array}{l}\text { Improved ability to work } \\
\text { with interdisciplinary team }\end{array}$ \\
\hline $\begin{array}{l}\text { Learning about work } \\
\text { environment }\end{array}$ & $\begin{array}{l}\text { Getting a "feel of } \\
\text { the floor" }\end{array}$ & $\begin{array}{l}\text { Better understanding of a } \\
\text { unit and an institutional system }\end{array}$ \\
\hline Being paid in nursing & Being in the workforce & $\begin{array}{l}\text { Ability to focus on nursing } \\
\text { as not employed elsewhere }\end{array}$ \\
\hline
\end{tabular}

Workplace outcomes. Workplace participants who worked directly with UGNs described their contribution as improving morale, helping with the workload and improving patient care.

Nurse participants who were working with UGNs also reported that they were enjoying teaching and refreshing their own nursing practice. This benefit for practising nurses is illustrated in the following comment: UGNs "are a good adjunct to care given. Helps 'old' nurses explain their practice. Gives new life to a unit.”

Recruitment. Most new graduates in both groups (UGN, other) were locally recruited; that is, their first RN positions were within the Health Service Areas where they were UGNs or where they completed their nursing program. The majority of new graduates $(65 \%)$ in both groups were recruited into casual positions. Of new graduates who were not locally recruited, over $50 \%$ accepted regular 
(non-casual) full-time or part-time positions. Although there were some new graduates who desired casual employment, the majority desired regular positions and took casual positions temporarily, with the goal of moving into a regular position when possible. There was no evidence that graduates who were offered regular positions declined them.

The availability of regular positions was the most critical factor in the recruitment and retention of new graduates. Practice representatives on the research team reported that availability of full-time positions for new graduates is influenced by several factors: casualization, turnover in permanent positions and downsizing, e.g., closing units and facilities.

Although the offer of full-time employment was a primary factor in new graduate recruitment, another important factor was the amount of debt load students accrued during their education. While fewer UGNs than other graduates reported accumulated debt greater than $\$ 30,000$, most still had substantial debt on graduation (45\% had debt greater than $\$ 20,000$ ). Graduates were offered substantial signing bonuses as well as other financial incentives by agencies in the United States (e.g., \$5,000 signing bonus, tuition for specialty courses, moving expenses). Such financial incentives, in addition to practice incentives (e.g., regular positions in area of interest, three-month mentoring), influenced both groups of new graduates in decisions about employment.

Other factors, as well, influenced the recruitment of new graduates. UGNs begin accruing seniority when they are hired as a UGN and, while they cannot use that seniority in applying for their first RN position, they can continue to build on that seniority if they accept employment within the agency of UGN employment. For the second RN position, all accrued seniority is applicable. Additionally, new graduates in both groups reported accepting positions on units where they had been employed as a UGN or where they completed a final preceptorship, because such positions offered employment with a familiar team of practitioners and provided opportunities for them to hone their skills as new RNs.

Transition to first RN position. New graduates were asked about their first RN position: what stood out and what helped or hindered their transition. For both groups of new graduates (UGN, other), the impact of being fully responsible stood out for them when they entered employment as an RN. One graduate described it as the "awesome reality of the responsibility - didn't hit me until after I finished school." Another graduate said, "mostly I think was the fact that I was on my own, and there was nobody to go get for help ... go get the RN, well, I am the RN." 
From their nursing program, all graduates spoke about the value of practice experiences and the knowledge and skills they gained from courses. Graduates who had been UGNs repeatedly emphasized the importance of the extra nursing practice experiences they gained while UGN employees. Both groups of new graduates also spoke strongly about the positive impact of supportive nurses and other coworkers, and adequate orientation and mentoring.

Many graduates, when asked about their transition to practice, reported that nothing hindered their transition. Some, however, commented on such challenges in the nurses' work world as casual work, staff shortages and heavy workloads. Overall, UGNs were more likely than other graduates to refer to their transition as smooth and comfortable, and they were less likely to experience inadequate mentoring and orientation as a hindrance.

Transition time was important, not only to new graduates but also to RN colleagues on the unit. The questions about transition time were derived from initial workplace nurses' descriptions of dimensions that are important when nurses are new to a particular job or unit. Graduates were asked about the length of time they took to feel comfortable on several dimensions of the $\mathrm{RN}$ role: (a) familiarize self with unit resources, (b) manage the workload similar to any RN, (c) form effective working relationships with members of the team and (d) know the practice guidelines specific to the unit's patient population. The new UGN graduates reported taking less transition time (one to four weeks) than other graduates on all four measures. UGN graduates also reported less orientation time than the other graduates. Less orientation time is consistent with evaluation results of a similar position in Alberta (T. Bonnah personal communication August 29, 2005).

Differences in transition time between UGNs and other graduates may be attributed to UGN prior experience with nurse employment. A reported difference of two to four weeks in transition time between groups has resource and patient safety implications for the employing organization. Greater orientation times within both groups (UGN, other) were related to acceptance of positions in specialty units, community agencies and agencies new to the graduates.

Job readiness. Workplace participants were questioned about their experiences working with new graduates who had UGN experience and those who did not. Workplace participants also were asked about differences in orientation and job readiness between the two groups. A definition of job readiness was not provided, so that the definition used by workplace participants would be self-created and grounded in their workplace context. 
Forty workplace participants identified themselves as working directly with new graduates who had UGN experience. Of these, $81 \%$ viewed new graduates who had UGN experience as more job-ready (e.g., requiring less guidance) than other new graduates and requiring a different orientation (e.g., less time or time focussed on issues beyond becoming familiar with the unit). When UGNs or other new graduates had previously worked on the same unit, workplace participants tended to trust them more because their capabilities were known and, not surprisingly, less guidance and supervision were required.

In other evaluation studies, workplace participants often described new graduates as having the knowledge and skills to be competent practising RNs, but still needing additional organizational and team skills to manage the whole RN workload (e.g., patient load, team coordination) and to work well within a multidisciplinary healthcare team (Collaborative Nursing Program in BC 2002; RNABC 2002, 2003). The results of the UGN evaluation would suggest that UGN graduates demonstrate, in addition to being practice-ready, the beginning organizational and team skills important to being job-ready.

Retention. The retention of new graduates and existing RNs was examined. During longitudinal followup, graduates were asked if they were still employed in the first RN position they were hired into upon graduation. Retention rates for both UGN and other new graduates declined by $13 \%$ at nine months. After 21 months, however, UGN graduate retention declined an additional 5\%, and other new graduate retention declined an additional 10\%. These findings are consistent with information from Capital Health Region in Alberta, where "a large number of undergraduate nurses remain as employees following graduation" (T. Bonnah personal communication August 29, 2005). Practice representatives on the research team stated that new graduates commonly accept summer jobs as entry positions because they are readily available owing to staff holidays. Such a decision often meant a move to another position after the end of the summer, and this affected retention rates.

Numeric retention data for existing nurses were not accessible; however, workplace nurses were asked their views about whether the presence of UGNs on the unit would affect retention of existing nurses. Workplace participants who were uncertain said that many factors affected retention, such as personal/family reasons, unsafe working conditions and a perceived lack of control in the practice setting. Other workplace participants who speculated that UGNs on units might affect staff retention cited such factors as reduced workload, increased staff morale, increased staff satisfaction and better patient care. 


\section{Discussion of Implementation and Outcome Results}

The results from the first two research questions on implementation and outcomes indicated that the UGN position was successfully implemented and a number of positive outcomes resulted for the student, new graduate and workplace. Outcomes for students and new graduates were consistent with reported benefits of co-op programs (Cusack 1990; Ishida et al. 1998; Siedenberg 1989; Ross and Marriner 1985).

Current literature supports the importance of the workplace outcomes that were associated with UGNs' work. Aiken et al. (2000) reported that RNs in hospitals with higher staffing and strong organizational support have been found to be less likely to report low-quality care than those working in hospitals with lower staffing. UGN employment similarly was associated with increased quality of care. O'BrienPallas et al. (2004: 12) reported that "ensuring that nurses can provide the quality nursing care that they deem appropriate will improve nurse perceptions of patient care quality over the last year." These authors also reported that intent to leave is less likely with an increase in nurse ratings of improved quality of nursing care on unit. Further, decreases in nursing workload have been associated with increases in favourable patient outcomes (Aiken et al. 2002; Needleman et al. 2002).

\section{What are the implications, plans and possibilities for future UGN employment programs?}

As one key information stated, "For people to bring up [the UNDP] as ... one of the core things we need to continue to do in this province, and to expand, tells me something about how [positively] the program is being received and valued." It is clear from the findings that this demonstration project addressed concerns of many in British Columbia about the nursing workforce, workplace and patient safety. As well, it prepared graduates to be more job-ready as they enter the nursing workforce.

Further exploration of the relationship between perceived transition time and job readiness is needed. While the evaluation study followed new graduates for nearly two years after they accepted their first $\mathrm{RN}$ position, a longer followup period is warranted to track retention. Nursing workforce statistics indicate that RN turnover of new graduates often occurs two to five years after graduation (SutherlandBoal 2004).

The availability of regular positions was the most critical factor in the recruitment and retention of new graduates. Chief nursing officers (provincial, national), as well as nursing unions, are concerned about the lack of available full-time positions for new graduates and report strategies to increase full-time positions (ONP 2004; BCNU 2005). 
Also, while evaluation results indicated overwhelming support for the UGN position, chief nursing officers expressed the need for quantification of some outcomes to strengthen an economic rationale for the UGN position. Further research is needed to enable interpretation of workplace results in relation to quality of work life and patient safety indicators, actual costs and costs avoided and, ultimately, cost implications of the UGN position.

Following the demonstration project and evaluation study, the UGN position continued to be funded in the original four Health Service Areas and was expanded to other BC health areas. In February 2005, announcements from the BC Ministry of Finance indicated funding for more full-time employment opportunities for new graduates and also for provision of UGN employment for every third- and fourth-year nursing student in the province.

\section{Conclusions}

Overall results indicate that the UNDP was well received as an innovation to support the workplace and nursing students. Findings were remarkably consistent across groups of participants (i.e., students, graduates, workplace nurses, faculty and key stakeholders). UGN learning outcomes were identified as increased confidence, improved organizational ability, expanded competency and greater ability to work with a team. Also noteworthy was the finding that the UNDP had positive effects on the workplace. Workplace participants reported that UGNs increased unit morale, helped with workload, improved patient care and enabled refreshment of RNs' practice. Clearly, the UNDP had an impact on the nursing workforce and workplace participants, and on nurses' evaluation of quality of patient care. The project also provided opportunities for graduates with UGN experience to become more job-ready and eased their transition to the $\mathrm{RN}$ role in comparison with other graduates. The concurrent evaluation study, through biannual dissemination of results over three years to all health authorities, professional organizations, policy makers and educators in British Columbia, enabled project improvement throughout the demonstration and provided evidence upon which expansion of the undergraduate nurse position across the province was based.

\section{Endnote}

Several projects involving nursing student employment have been developed since the implementation of the Undergraduate Nurse Demonstration Project. Two nursing schools in Nova Scotia introduced cooperative education into their nursing programs in 2000, and co-op continues to be funded by the Department 
of Health. According to Downe-Wamboldt (2004), "the 10-week employment in a clinical setting ... is highly valued by student, preceptors and the institutions in which they are placed."

In 2004 and 2005, the University of Alberta School of Nursing, in partnership with the local health region, offered a 10-week summer internship option (clinical course between years 3 and 4 ) for students who were successful in the competition for internship positions. The student intern was evaluated by the instructor in conjunction with the nurse manager, received academic credit for the course and was paid by the health region (M. Rich personal communication September 12, 2005).

While these co-op and internship experiences have a formal education component, other employment options developed for students have not included a formal educational link. Three provinces reported student nurse employment initiatives in which students are hired as unregulated workers or auxiliaries to nursing staff (L. Banerjee personal communication August 29, 2005; M. Bonathan personal communication August 29, 2005; D. Phillipchuk personal communication August 26,2005). In Alberta, after their third year, students are hired as undergraduate nursing employees and function within a job description specific to their level of competency.

\section{Acknowledgments}

The authors wish to acknowledge the research team, specifically:

From practice: Deanna Hutchings (South Vancouver Island), Patty Skultety (North Okanagan), Monica Adamack (South Okanagan), Lise Poirier (Chilcotin, Cariboo, Thompson).

From education: Joan Douglas (Camosun College), Mary Ellen Purkis and Melody Quinn (University of Victoria), Maureen Parkes (Malaspina University College), Leslie McCreary (University of British Columbia Okanagan), Cheryl Zawaduk (Thompson Rivers University).

Thanks are also due to Christina McKay (former University of Victoria nursing student) and to all study participants: students, nurses, faculty, administrators and policy makers.

Ethics Approval for Human Participant Research was granted by the Office of Research at University of Victoria for the Paid Undergraduate Nurse Evaluation, and funding was provided by the BC Ministry of Health Services.

Address correspondence to: Lucia Gamroth, RN, PhD, School of Nursing University of Victoria, P.O. Box 1700, Victoria, BC, V8W 2Y2, Canada. E-mail: lgamroth@uvic.ca

\section{References}

Aiken, L., S. Clarke and D. Sloane. 2002. "Hospital Staffing, Organization, and Quality of Care:

Cross-National Findings." International Journal for Quality in Health Care 14(1): 5-13.

British Columbia Nurses Union. 2005. “Creating Change.” BCNU Update, 24(4):16.

Collaborative Nursing Program (CNP) in British Columbia. 2002. Program Evaluation Report. Victoria, BC: Author.

Cusack, J.M. 1990. “Cooperative Education: An Innovative Recruitment Technique." Dimensions of Critical Care Nursing 9: 119-25. 
Downe-Wamboldt, B. 2004. “Undergraduate Nursing Program.” Network Newsletter. Dalhousie University School of Nursing. Retrieved August 12, 2006. $<$ http://nursing.dal.ca/Files/networknewsletter04.pdf >.

Fitt, D.X. and M. Heverly. 1990. Involving the Private Sector with Higher Education." Journal of Cooperative Education 27(3): 64-72.

Gamroth, L., C. Budgen and M. Lougheed. 2004. Feasibility and Outcomes of Paid Undergraduate Student Positions for Designated Health Service Areas in BC: Year Three Final Report. Victoria, BC: University of Victoria School of Nursing.

Green, L., M. George, M. Daniel, C. Frankish, C. Herbert, W. Bowie and M. O'Neill. 1995. Study of Participatory Research in Health Promotion. University of British Columbia Institute of Health Promotion Research and the BC Consortium for Health Promotion Research. Ottawa: Royal Society of Canada.

Heinemann, H.N. and A.A. De Falco. 1992. “Dewey's Pragmatism: A Philosophical Foundation for Cooperative Education." Journal of Cooperative Education 27(1): 38-44.

Ishida, D.N., M.A. Merilee and D.S. Leah. 1998. "Cooperative Education in Nursing: A Strategy for Increasing Marketability." Journal of Nursing Education 37(6): 260-63.

Kee, G. and F. Ryser. 2001. "Work-Study Scholarship Program for Undergraduate Nursing Students: A Win-Win Service Education Partnership." Nursing Administration Quarterly 26(1): 29-34.

Needleman, J., P. Buerhaus, S. Mattke, M. Stewart and K. Zelevinsky, 2002. "Nurse Staffing Levels and the Quality of Care in Hospitals." New England Journal of Medicine 346(22): 1715-22.

O’Brien-Pallas, L., D. Thomson, L. McGillis Hall, G. Pink, M. Kerr, S. Wang, X. Li and R. Meyer. 2004 (September). "Evidence-Based Standards for Measuring Nurse Staffing and Performance." Canadian Health Services Research Foundation Project No. RC1-0621-06. Retrieved August 12, 2006. <http:/ www.chsrf.ca/final_research/ogc/pdf/obrien_final.pdf>.

Office of Nursing Policy (ONP), Health Canada. 2004 (April-May). "Taking a Pulse on the Issue of New Grads and Full Time Work: What's Going on Across the Country This Spring?” ONP Newsletter. Retrieved August 12, 2006. <http://www.hc-sc.gc.ca/hcs-sss/pubs/care-soins/onp-bpsinewsbull/2004-apr-avr-ma_e.html >.

Phillipchuk, D., Alberta Association of Registered Nurses (personal communication, August 26, 2005).

Registered Nurses Association of British Columbia (RNABC). 2002. New Graduate Nurse Survey 2002. Vancouver: Author.

Registered Nurses Association of British Columbia (RNABC). 2003. New Graduate Nurse Survey 2003. Vancouver: Author.

Ross, S. and A. Marriner. 1985. "Cooperative Education: Experienced Based Learning." Nursing Outlook 33(4): 177-80.

Ryder, K.G. 1987. “Social and Educational Roots.” In J.W. Wilson and K.G. Ryder, eds., Cooperative Education in a New Era (pp. 1-12). San Francisco: Jossey-Bass.

Siedenberg, J.N. 1989. "Investing in Nursing Education: Some Evidence of Immediate Private Monetary Nenefits." Journal of Nursing Education 28(5): 210-14.

Statistical Package for Social Sciences. 2002. Version 11.5 for Windows. Retrieved August 12, 2006. $<$ http://www.spss.com>.

Sutherland-Boal, A. 2004 (April). “Respondent Panel.” Presentation at a Vancouver Island Health Authority Workshop, Victoria, BC. 